\title{
Cioran na RUa, Desenhos de Dan Perjovschi
}

Os desenhos foram feitos pelo artista romeno Dan Perjovschi no âmbito do projeto Cioran na rua, organizado em abril de 2011 pela Embaixada da França na Romênia, pelo Instituto Francês de Bucareste, com a participação do artista, para celebrar os 100 anos de nascimento do escrito e filósofo romeno Emil Cioran.
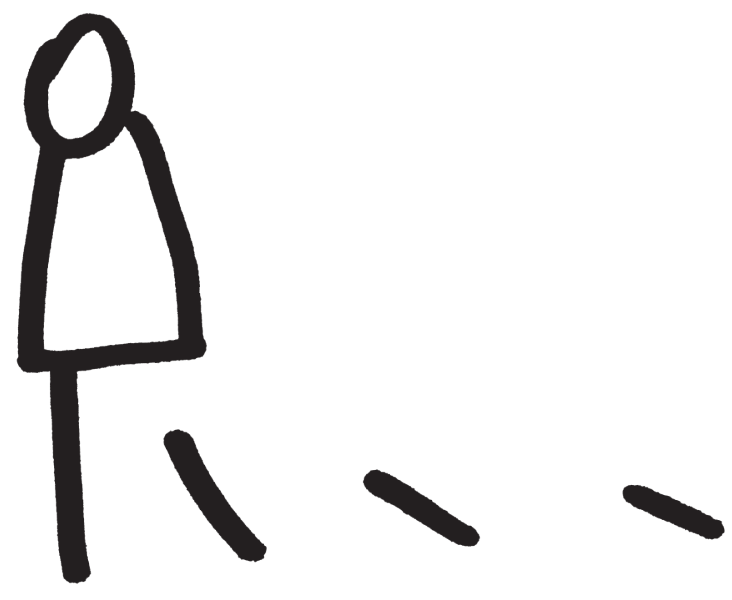

"Să trăiești înseamnă să pierzi teren."

"Vivre, c'est perdre du terrain. "

(Emil Cioran, Despre neajunsul de a te fi născut / De l'inconvénient d'être né) 


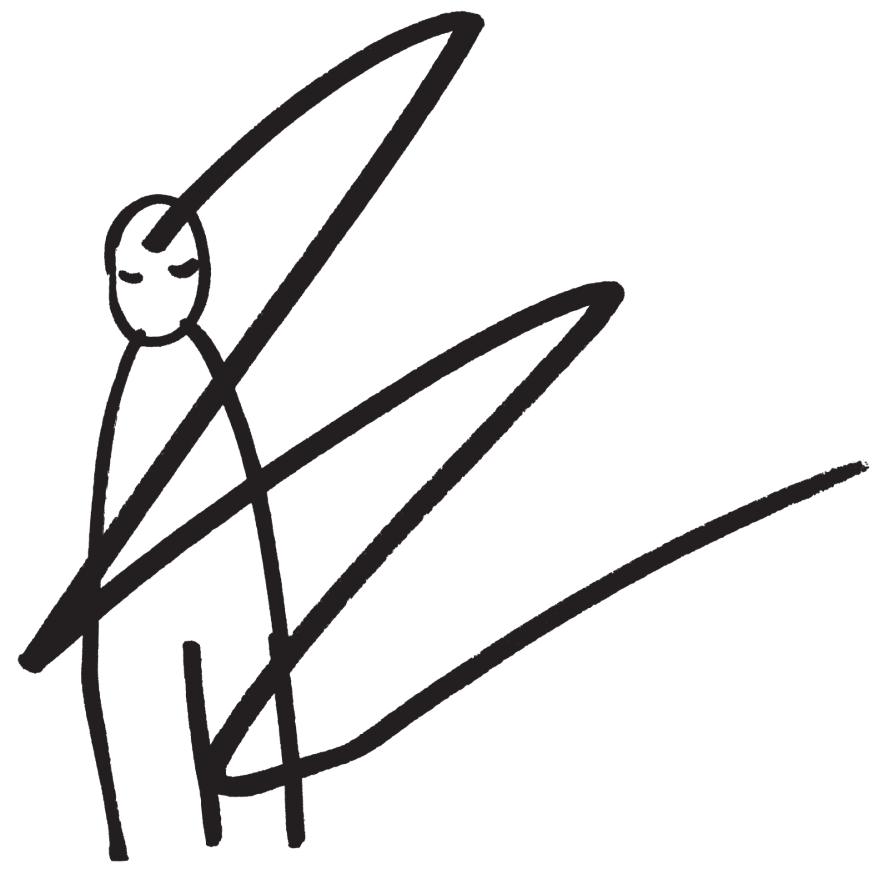

"Ceea ce știu distruge ceea ce vreau."

"Ce que je sais démolit ce que je veux. "

(Emil Cioran, Aveux et anathèmes / Mărturisiri și anateme) 


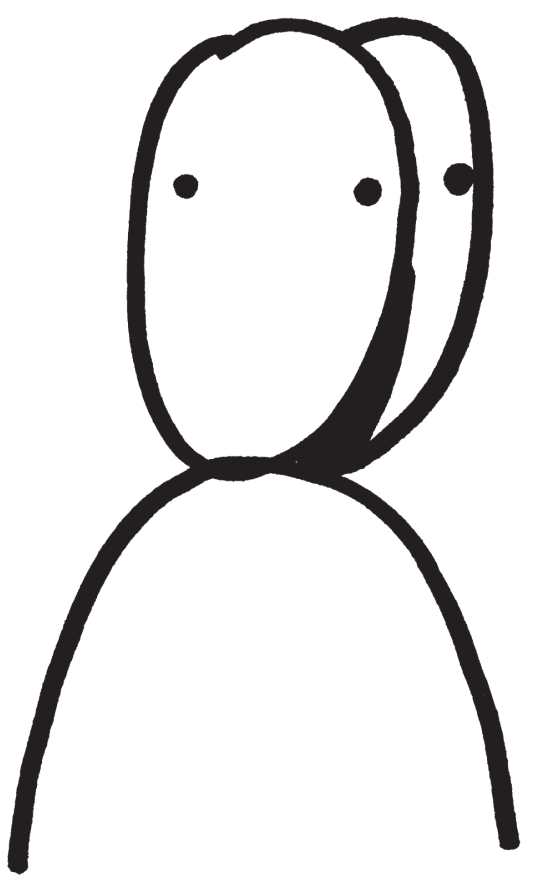

"A exista e un plagiat."

"Exister est un plagiat."

(Emil Cioran, Sfîrtecare / Écartèlement) 


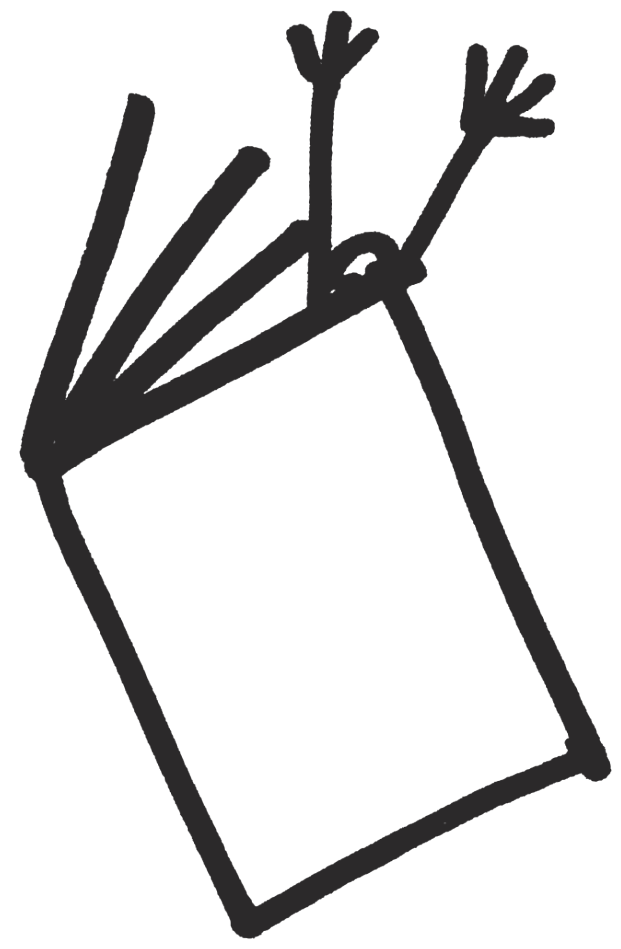

"O carte trebuie să adîncească răni, să le provoace chiar.

O carte trebuie s" fie o primejdie."

«Un livre doit remuer les plaies, en provoquer même.

Un livre doit être un danger. "

(Emil Cioran, Sfîrtecare / Écartèlement) 


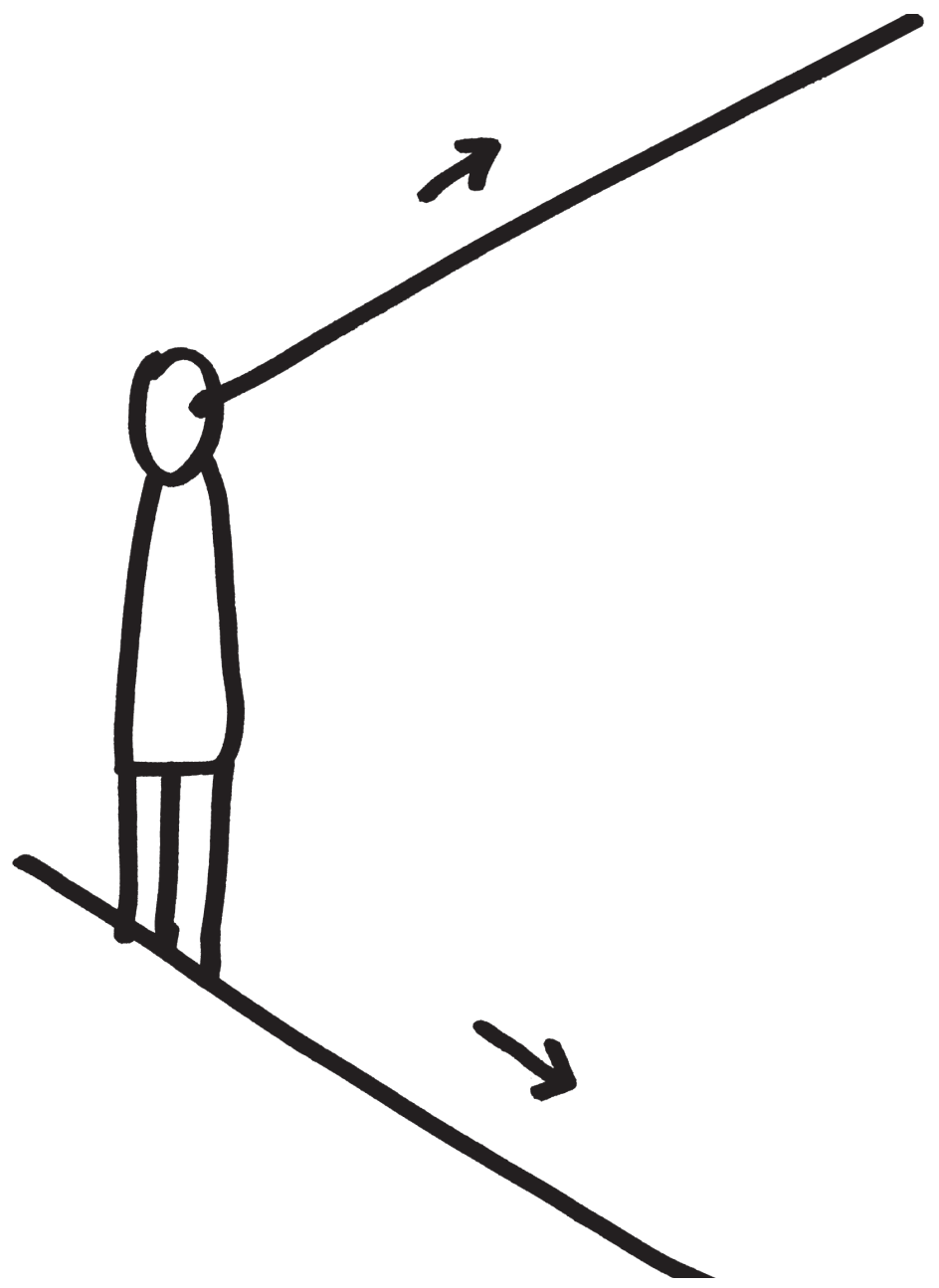

"Să speri înseamnă să dezminți viitorul."

"Espérer, c'est démentir l'avenir. »

(Emil Cioran, Silogismele amărăciunii / Syllogismes de l'amertume) 